\title{
miRNA-regulated expression of oncogenes and tumor suppressor genes in the cisplatin-inhibited growth of $\mathrm{K562}$ cells
}

\author{
SHU-YANG XIE ${ }^{1 *}$, YOU-JIE LI ${ }^{1 *}$, PING-YU WANG ${ }^{1}$, FEI JIAO ${ }^{1}$, SHUAI ZHANG ${ }^{1}$ and WEN-JUAN ZHANG ${ }^{2}$ \\ ${ }^{1}$ Institute of Medical Molecular Genetics, Department of Biochemistry and Molecular Biology, Bin Zhou Medical University, \\ Yan Tai, Shandong 264003; ${ }^{2}$ YanTai Shan Hospital, Yan Tai, Shandong 264000, P.R. China
}

Received December 16, 2009; Accepted February 10, 2010

DOI: $10.3892 /$ or_00000813

\begin{abstract}
To explore the mechanism of apoptosis induced by cisplatin, the expression of microRNAs (miRNAs) and regulating genes in K562 cells was analyzed using reverse transcription PCR, quantitative real-time PCR and enzymelinked immunosorbent assays. Our results showed that miR-16, miR-34a-c, miR-17-5p and miR-125 were upregulated, and their associated oncogenes (BCL2, E2F1 and E2F3, respectively) were down-regulated after cisplatin treatment. We also showed that miR-106 and miR-150 were down-regulated while their target genes (RB1 and P53, respectively) were up-regulated after cisplatin treatment. Moreover, miR-16, miR-34a-c and miR-17-5p proved to be upstream factors, regulating the expression of BCL2, E2F1 and E2F3, respectively. The oncogene E2F3 was downregulated when RB1 expression was increased after treatment with antisense oligonucleotides (ASO). Similarly, BCL2 and E2F3 were down-regulated when P53 expression was elevated by ASO treatment. The study demonstrated that cisplatin induces K562 cells to apoptosis by reducing miR106 which up-regulates RB1 or by inhibiting miR-150 which increases P53 expression.
\end{abstract}

Correspondence to: Dr Shu-yang Xie, Institute of Medical Molecular Genetics, Department of Biochemistry and Molecular Biology, Bin Zhou Medical University, No. 346 Guan Hai Road, Lai Shan, Yan Tai, Shandong 264003, P.R.China

E-mail: shuyangxie@yahoo.com.cn

${ }^{*}$ Contributed equally

Abbreviations: miRNAs, microRNAs; ASO, antisense oligonucleotides; CDDP, cisplatin; FLICE, Fas-associated death domainlike interleukin-1ß-converting enzyme; PIDD, p53-induced protein with a death domain; RISC, RNA-induced silencing complex; CLL, chronic lymphocytic leukemia; RT-PCR, reverse transcription PCR; MTT, 3-(4,5-dimethylthiazol-2-yl)-2,5-diphenyltetrazolium bromide; qRT-PCR, quantitative real-time PCR; ELISA, enzyme-linked immunosorbent assay; $\mathrm{IC}_{50}, 50 \%$ growth-inhibitory concentration; $\mathrm{RB}$, retinoblastoma

Key words: microRNA, leukemia, oncogene, cisplatin, antisense oligonucleotides

\section{Introduction}

Cisplatin [cis-diamminedichloroplatinum (II), CDDP] has been used in numerous studies to induce the apoptosis of carcinoma cells. Cells, growth-arrested by cisplatin treatment, showed a higher spontaneous cell death rate than that of untreated proliferating cells. Cisplatin is an effective chemotherapeutic agent that elicits its antineoplastic activity by binding to DNA and disrupting template functions (1). Studies have shown that cisplatin strongly inhibits the decatenation activity of topoisomerase II (2), which is critical for relieving the torsional stress that occurs during replication and transcription and for daughter strand separation during mitosis. Cisplatin can also regulate the expression of oncogenes or tumor suppressor genes to induce tumor cell apoptosis. Likewise, these genes can predict the cisplatin sensitivity of cancer cell lines. Cisplatin was found to induce p53dependent Fas-associated death domain-like interleukin-1ßconverting enzyme (FLICE)-like inhibitory protein (FLIP) degradation in chemosensitive ovarian cancer cells. A recent study demonstrated that cisplatin induces the PIDD (p53induced protein with a death domain)-dependent activation of caspase-2. In turn, caspase- 2 cleaves and activates Bid, resulting in the oligomerization of Bak and the release of cytochrome $\mathrm{c}$, resulting in a synergistic induction of cisplatininduced cytotoxicity (3). Farnebo et al found that single nucleotide polymorphisms in the DNA repair genes XRCC3241 and XPD751 influence the intrinsic cisplatin sensitivity and that XRCC3241, XPD751, EGFR, Hsp70, $\mathrm{Bax}$ and Bcl-2 predict the cisplatin sensitivity of head and neck cancer cell lines (4).

A family of 20- to 22-nucleotide (nt) noncoding RNAs termed microRNAs (miRNAs) has been identified in eukaryotic organisms ranging from nematodes to humans (5-7). After maturation, these small RNAs are incorporated into the RNA-induced silencing complex (RISC), through which they mediate post-transcriptional gene silencing of specific mRNA targets (8). miRNAs have a profound impact on many processes that are frequently disrupted during malignant transformation, including cell proliferation, apoptosis and stress responses. miRNAs have emerged as candidate components of oncogene and tumor-suppressor networks. miR-372/373 and miR-155/BIC $(9,10)$ have been implicated as proto-oncogenes in B-cell lymphomas and testicular cancers. On the other hand, miR-15/16 is 
Table I. Oligonucleotide primers for the PCR analysis.

\begin{tabular}{llcl}
\hline Primers & \multicolumn{1}{c}{ Sequences } & Temperature & Notation \\
\hline b1 & 5'-ttgccacggtggtggagga-3' & $53^{\circ} \mathrm{C}$ & b1 and b2 were used to amplify human BCL2 mRNA (258 bp) \\
b2 & 5'-acagccaggagaaatcaaacag-3' & & \\
p1 & 5'-atggaggagccgcagtca-3' & $53^{\circ} \mathrm{C}$ & p1 and p2 were used to amplify human P53 mRNA (345 bp) \\
p2 & 5'-atgcaagaagcccagacg-3' & & \\
e11 & 5'-ttgccaagaagtccaagaac-3' & $55^{\circ} \mathrm{C}$ & e11 and e12 were used to amplify human E2F1 mRNA (494 bp) \\
e12 & 5'-tgtggtgagggatgaggg-3' & & \\
e31 & 5'-ttgaacaaggcagcagaa-3' & $53^{\circ} \mathrm{C}$ & e31 and e32 were used to amplify human E2F3 mRNA (249 bp) \\
e32 & 5'-cagtttgaggtccagggt-3' & & \\
R1 & 5'-aaccctcctaaaccactg-3' & $54^{\circ} \mathrm{C}$ & R1 and R2 were used to amplify human RB1 mRNA (490 bp) \\
R2 & 5'-gggccattcttactatcc-3' & & \\
B1 & 5'-ctacaatgagctgcgtgtggc-3' & $55^{\circ} \mathrm{C}$ & B1 and B2 were used to amplify human B-actin mRNA (270 bp) \\
B2 & 5'-caggtccagacgcaggatggc-3' & & \\
\hline
\end{tabular}

frequently deleted in patients with chronic lymphocytic leukemia (CLL).

To date, the mechanism by which cisplatin induces apoptosis in tumor cells particularly concerning its effect on expression of miRNAs requires further study. Therefore, we studied its effect on oncogenes, tumor suppressor genes and their correlated miRNAs. Our results showed that cisplatin induced apoptosis in K562 cells by modulating miRNA expression to affect the RB1 and P53 pathways.

\section{Materials and methods}

Cell culture and treatment with cisplatin. Human leukemia K562 cells were obtained from Shanghai Institute of Cell Biology, Chinese Academy of Sciences. Cells were cultured in RPMI-1640 medium (Hyclone) with $10 \%$ calf serum $\left(37^{\circ} \mathrm{C}\right.$ with $\left.5 \% \mathrm{CO}_{2}\right)$ for $18-24 \mathrm{~h}$ before drug treatment. Cells $\left(5 \times 10^{5}\right)$ were exposed to various concentrations $(0-20 \mu \mathrm{M})$ of cisplatin (synthesized from QiLu Pharmaceutical Co., Ltd) and exposure intervals $(12-36 \mathrm{~h})$.

Detection of growth inhibition rate After cells were treated with cisplatin, the MTT [3-(4,5-dimethylthiazol-2-yl)-2,5diphenyltetrazolium bromide] (Sigma, USA) assay was carried out to investigate the growth inhibition rate in the cells as follows: $1 \times 10^{4}$ cells were cultured in each well of 96-well flat-bottom microtiter plates; $4 \mathrm{~h}$ before the end of incubation, $10 \mu \mathrm{l}$ MTT $(5 \mathrm{mg} / \mathrm{ml})$ was added, and the supernatant was removed; $100 \mu 1$ dimethyl sulfoxide was added to determine the OD value at $570 \mathrm{~nm}$ using an Enzymelinked immunosorbent assay (ELISA) reader (ELX800). Percentage of growth inhibition $=($ ODcontrol - ODsample $) /$ ODcontrol x $100(\%)$

Reverse transcription polymerase chain reaction (RT-PCR). K562 cells were collected, and cDNA was synthesized from their total RNA which was extracted using Trizol reagent (Invitrogen). After the RT reaction, BCL2, E2F1, E2F3, P53 and $R B 1$ genes were detected using PCR; $\beta$-actin was used as the internal control. These genes were amplified for 26 cycles in a thermocycler (Eppendorf): denaturing at $94^{\circ} \mathrm{C}$ for $30 \mathrm{sec}$, annealing for $30 \mathrm{sec}$, followed by extension at $72^{\circ} \mathrm{C}$ for $45 \mathrm{sec}$. The primers and annealing temperatures are listed in Table I. PCR products were analyzed using gel electrophoresis in $2 \%$ agarose gel.

Quantitative real-time-PCR ( $q R T-P C R)$. Quantitative realtime-PCR was performed using SuperTaq Polymerase (Ambion) and a mirVana qRT-PCR miRNA Detection Kit (Ambion), using mirVana qRT-PCR primer sets specific for miR-16, miR-17-5p, miR-34a-c and the other miRNAs following the manufacturer's instructions. Human 5S rRNA served as the positive control. To evaluate the relative abundance of each mRNA, total RNAs from K562 cells were isolated and subjected to treatment with reverse transcriptase followed by qRT-PCR using the RG3000 System (Corbett Research) with the Quantitect SYBR Green Kit (Qiagen) as follows: an initial denaturation at $95^{\circ} \mathrm{C}$ for $3 \mathrm{~min}$, followed by 35 cycles at $95^{\circ} \mathrm{C}$ for $30 \mathrm{sec}$, annealing for $30 \mathrm{sec}$ and extension at $72^{\circ} \mathrm{C}$ for $30 \mathrm{sec}$. Primers and annealing temperatures are listed in Table I. Fluorescence was detected at $585 \mathrm{~nm}$ at each extension step at $72^{\circ} \mathrm{C}$. $\beta$-actin mRNAs were used as internal controls. The relative mRNA abundance was determined by the ratio of sample to control.

Enzyme-linked immunosorbent assay (ELISA). K562 cells were lysed [lysis buffer: $0.15 \mathrm{M} \mathrm{NaCl}, 5 \mathrm{mM}$ EDTA (pH 8.0), $1 \%$ Triton X-100, $10 \mathrm{mM}$ Tris-Cl (pH 7.4), $100 \mathrm{mM}$ PMSF and $5 \mathrm{M} \mathrm{DTT}$ ) and incubated in a 96-well plate, followed by the addition of goat anti-human antibodies against BCL2 (1:400), E2F1, E2F3 (1:400, 1:400), RB1 (1:500) and P53 (1:300, 1:400) (all from Immunoleader, Boster) according to the manufacturer's instructions. Antibody binding was shown by incubation with rabbit anti-goat IgG/HRP-labeled secondary antibodies (Beijing Zhong Shan-Golden Bridge Technology Co., Ltd.) and their substrates in turn. The optical 
Table II. Sequences of the chemically synthesized RNAs for miRNA ${ }^{\mathrm{a}}$.

\begin{tabular}{|c|c|c|}
\hline Oligos & & Sequence $\left(5^{\prime} \rightarrow 3^{\prime}\right)$ \\
\hline miR-16 & $\begin{array}{l}\text { Sense } \\
\text { Antisense }\end{array}$ & $\begin{array}{l}\text { uagcagcacguaaauauuggcg } \\
\text { ccaauauuuacgugcugcuauu }\end{array}$ \\
\hline miR-17-5 & $\begin{array}{l}\text { Sense } \\
\text { Antisense }\end{array}$ & $\begin{array}{l}\text { caaagugcuuacagugcagguag } \\
\text { accugcacuguaagcacuuuguu }\end{array}$ \\
\hline miR-34a & $\begin{array}{l}\text { Sense } \\
\text { Antisense }\end{array}$ & $\begin{array}{l}\text { uggcagugucuuagcugguugu } \\
\text { aaccagcuaagacacugccauu }\end{array}$ \\
\hline $\operatorname{miR}-34 b$ & $\begin{array}{l}\text { Sense } \\
\text { Antisense }\end{array}$ & $\begin{array}{l}\text { caaucacuaacuccacugccau } \\
\text { ggcaguggaguuagugauuguu }\end{array}$ \\
\hline $\operatorname{miR}-34 c$ & $\begin{array}{l}\text { Sense } \\
\text { Antisense }\end{array}$ & $\begin{array}{l}\text { aggcaguguaguuagcugauugc } \\
\text { aaucagcuaacuacacugccuuu }\end{array}$ \\
\hline miR-106 & $\begin{array}{l}\text { Sense } \\
\text { Antisense }\end{array}$ & $\begin{array}{l}\text { aaaagugcuuacagugcagguag } \\
\text { accugcacuguaagcacuuuuuu }\end{array}$ \\
\hline $\operatorname{miR}-125$ & $\begin{array}{l}\text { Sense } \\
\text { Antisense }\end{array}$ & $\begin{array}{l}\text { ucccugagacccuuuaaccuguga } \\
\text { acagguuaaagggucucagggauu }\end{array}$ \\
\hline miR-150 & $\begin{array}{l}\text { Sense } \\
\text { Antisense }\end{array}$ & $\begin{array}{l}\text { ucucccaacccuuguaccagug } \\
\text { cugguacaaggguugggagauu }\end{array}$ \\
\hline nc (control) & $\begin{array}{l}\text { Sense } \\
\text { Antisense }\end{array}$ & $\begin{array}{l}\text { caguacuuuuguguaguacaa } \\
\text { guacuacacaaaaguacuguu }\end{array}$ \\
\hline
\end{tabular}

aThe selected miRNAs were chemically synthesized in the form of small interfering RNA (siRNA) duplexes.

Table III. Sequences of the antisense molecules used in this study.

\begin{tabular}{ll}
\hline ASO & \multicolumn{1}{c}{ Sequence $\left(5^{\prime} \rightarrow 3^{\prime}\right)$} \\
\hline Aso-miR-16 (anti-16) & $\begin{array}{l}\text { cgccaauauuuacgugcugcua } \\
\text { cuaccugcacuguaagcacuuug } \\
\text { Aso-miR-17-5p (anti-17-5) }\end{array}$ \\
Aso-miR-20 (anti-20) & aaccugcacuauaagcacuuua \\
Aso-miR-34a (anti-34a) & auggcaguggaguuagugauug \\
Aso-miR-34b (anti-34b) & agcaaucagcuaacuacacugccu \\
Aso-miR-34c (anti-34c) & cuaccugcacuguaagcacuuuu \\
Aso-miR-106 (anti-106) & ucacagguuaaagggucucaggga \\
Aso-miR-125 (anti-125) & cacugguacaaggguugggaga \\
Aso-miR-150 (anti-150) & utucuccgaacgugucacgu \\
Anti-nc (control) & \\
\hline
\end{tabular}

density of the reaction was determined spectrophotometrically at $450 \mathrm{~nm}$ using an ELX800 ELISA reader.

MicroRNAs/inhibitors and transfection. The sequences of the miRNAs or its inhibitors [2'-OMe-modified antisense oligonucleotides (ASOs)] used in this study are listed in Tables II and III, respectively. The inhibitors each contained a 3'-C-3-containing amino linker and 2'-OMe modifications
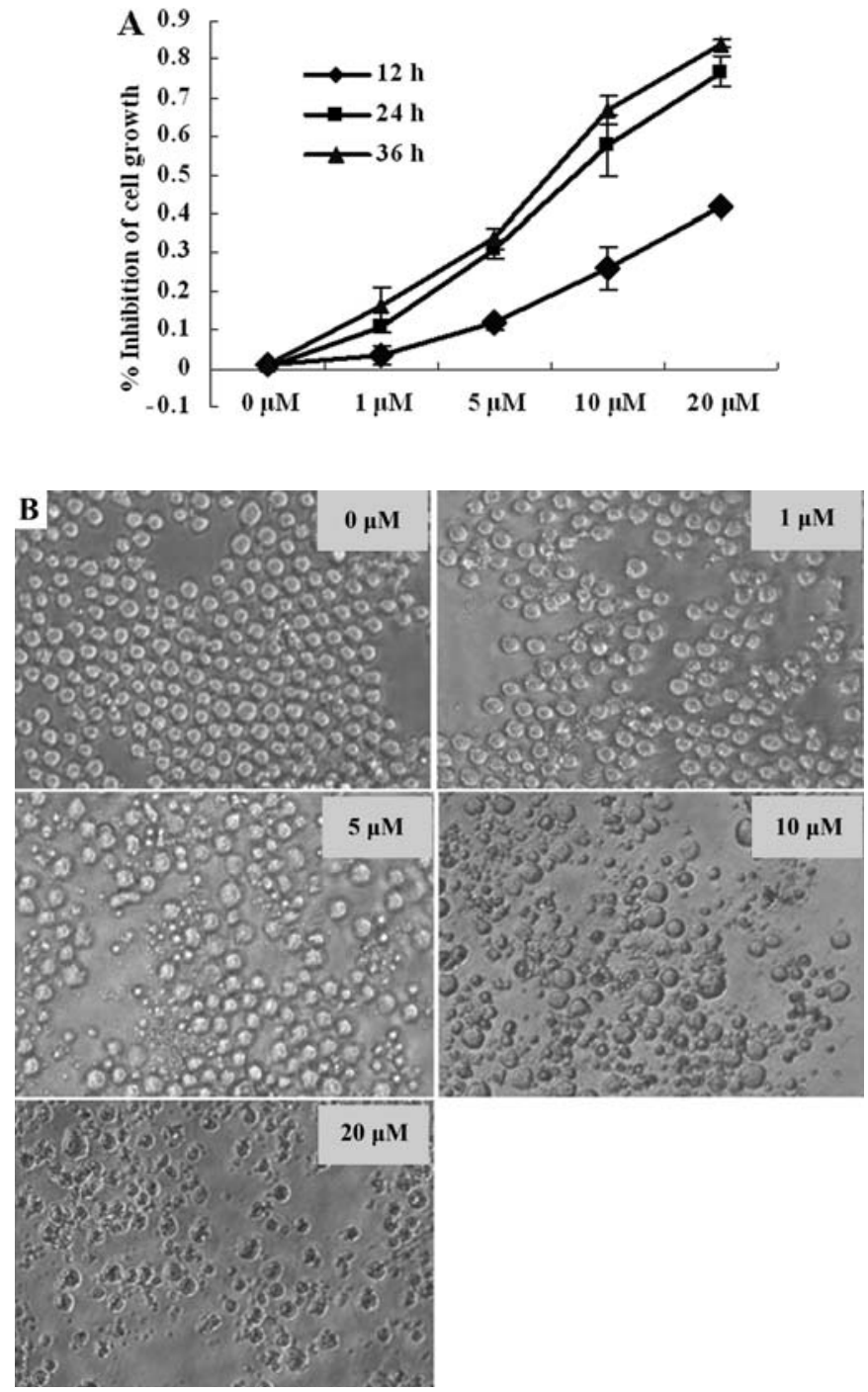

Figure 1. Effect of cisplatin concentration and exposure intervals on the cell growth of K562 cells was studied by MTT assay and microscopy. (A) Cells were treated with $0-20 \mu \mathrm{M}$ cisplatin at different exposure intervals. (B) Morphological changes of cells treated with 0-20 $\mu \mathrm{M}$ cisplatin at $24 \mathrm{~h}$.

at every base. All transfections were carried out in triplicate. For transfection, a mixture of $5 \mu 1 \mathrm{NeoFx}$ (Ambion) and $50 \mu 1$ Opti-MEM was added to each 12-well plate. After incubation for $10 \mathrm{~min}$ at room temperature, $15 \mu \mathrm{M}$ of inhibitors were diluted with $50 \mu 1$ Opti-MEM already aliquoted into each well and incubated for another $10 \mathrm{~min}$ at room temperature. Diluted cell suspension mixture $(900 \mu \mathrm{l})$ containing $2 \times 10^{5}$ cells was then added on top of the complex. The medium was changed after $24 \mathrm{~h}$, and samples were assayed after $72 \mathrm{~h}$.

Statistical analysis. SAS software was used to analyze the significance of all results. The Student's t-test was used for inter-group comparison. A p-value $<0.05$ was considered significant.

\section{Results}

Changes in mRNA after cisplatin induction of apoptosis. After incubation with cisplatin, we found that the $50 \%$ growth-inhibitory concentration $\left(\mathrm{IC}_{50}\right)$ of cisplatin in $\mathrm{K} 562$ cells was $10 \mu \mathrm{M}$ at $24 \mathrm{~h}$ (Fig. 1A). The number of tumor 

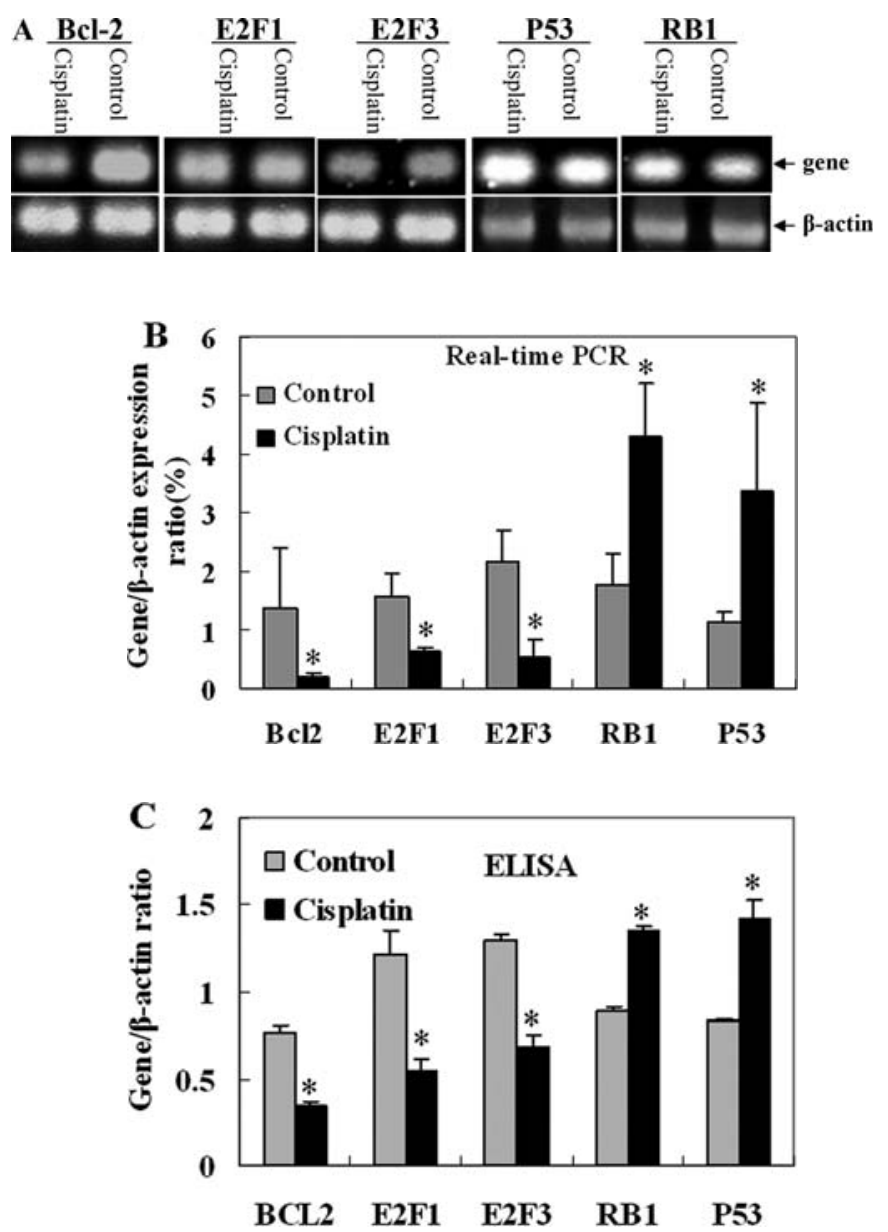

Figure 2. Changes in mRNA expression of BCL2, E2F1, E2F3, RB1 and P53 in K562 cells after cisplatin treatment. BCL2, E2F1, E2F3, RB1 and P53 were detected by (A) RT-PCR, (B) real-time PCR and (C) ELISA.

cells decreased, and apoptotic cells were found in the cisplatin-treated groups (Fig. 1B). BCL2, E2F1and E2F3 have oncogenic roles in tumor proliferation, while RB1 and P53 are tumor suppressor genes $(11,12)$. These genes are common in tumor formation and therefore were chosen for study in K562 cells after cisplatin treatment. Changes in mRNA expression of BCL2, E2F1, E2F3, RB1 and P53 after treatment with cisplatin were further established using RTPCR and ELISA analyses. The results showed that the BCL2, E2F1 and E2F3 genes had much lower expression, and RB1 and P53 had obviously higher expression in the cisplatintreated K562 cells compared with the controls (Fig. 2A-C).

Effect of cisplatin on gene-regulated miRNA expression in K562 cells. The relationship between the above genes and the targeted miRNAs was predicted using microRNA TargetScan software online (http://www.targetscan.org/index.html). This site provides a comprehensive analysis of the targeting genes of miRNAs. The results showed that the above gene expression might be targeted by miR-16/34a-c (BCL2), miR17-5p (E2F1), miR-125/34a-c (E2F3), miR-106 (RB1) and miR-150 (P53). Expression of gene-regulated miRNAs was further analyzed using RT-PCR and real-time PCR. The results showed that the cisplatin treatment up-regulated expression of miR-16, miR-34a-c, miR-17-5p and miR-125,
A
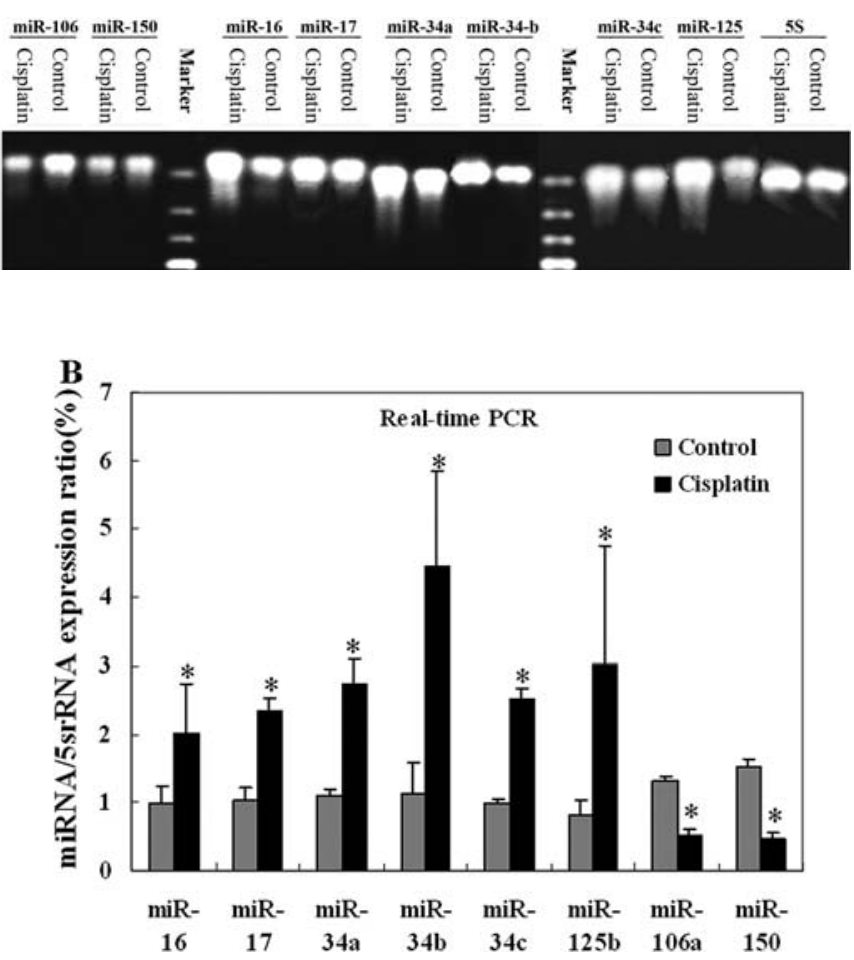

Figure 3. Correlative expression of miRNAs was analyzed in K562 cells after cisplatin treatment. (A) RT-PCR; (B) real-time PCR. *Significant difference $(\mathrm{p}<0.05)$.

and down-regulated expression of miR-106 and miR-150 (Fig. 3A and B).

Further analysis of the correlative expression of miRNAs and their targeting genes using ASO. The antisense inhibition of miRNAs using 2'-OMe-modified ASOs in cell culture, and C. elegans and Drosophila embryos has been reported (13). To establish whether expression of the BCL2, E2F1, E2F3, RB1 and P53 genes was regulated by their targeted miRNAs (as predicted by microRNA TargetScan software), K562 cells were treated with ASO. miRNA expression was downregulated after ASO treatment (Fig. 4A and B), and E2F1 was down-regulated when cells were treated with miR-17-5 RNA (Fig. 5A). Moreover, as expression of miR-17-5p was down-regulated using ASO, expression of its target gene, E2F1, was higher in the treated group than in the control (Fig. 4C), indicating that miR-17-5p is an upstream regulatory factor for E2F1 expression and a component of the apoptosisinducing mechanism of cisplatin. Expression of E2F3 was reduced when inducing miR34a-c or miR-125 oligos (Fig. 5B). With the exception of miR34a-c, our results also demonstrated miR-125 to be an upstream miRNA regulator of E2F3 expression and a component of the apoptosis-inducing mechanism of cisplatin in K562 cells (Fig. 4D). Similarly, when cells were treated with miR-16 RNA, BCL2 was downexpressed (Fig. 5C). BCL2 expression was increased at varying levels when miR-16 expression was down-regulated by ASOs (anti-16) (Fig. 4E). Our study also found that miR-34a-c inhibited BCL2 expression upon the addition of ASO or miRNA (Figs. 4E and 5C). 

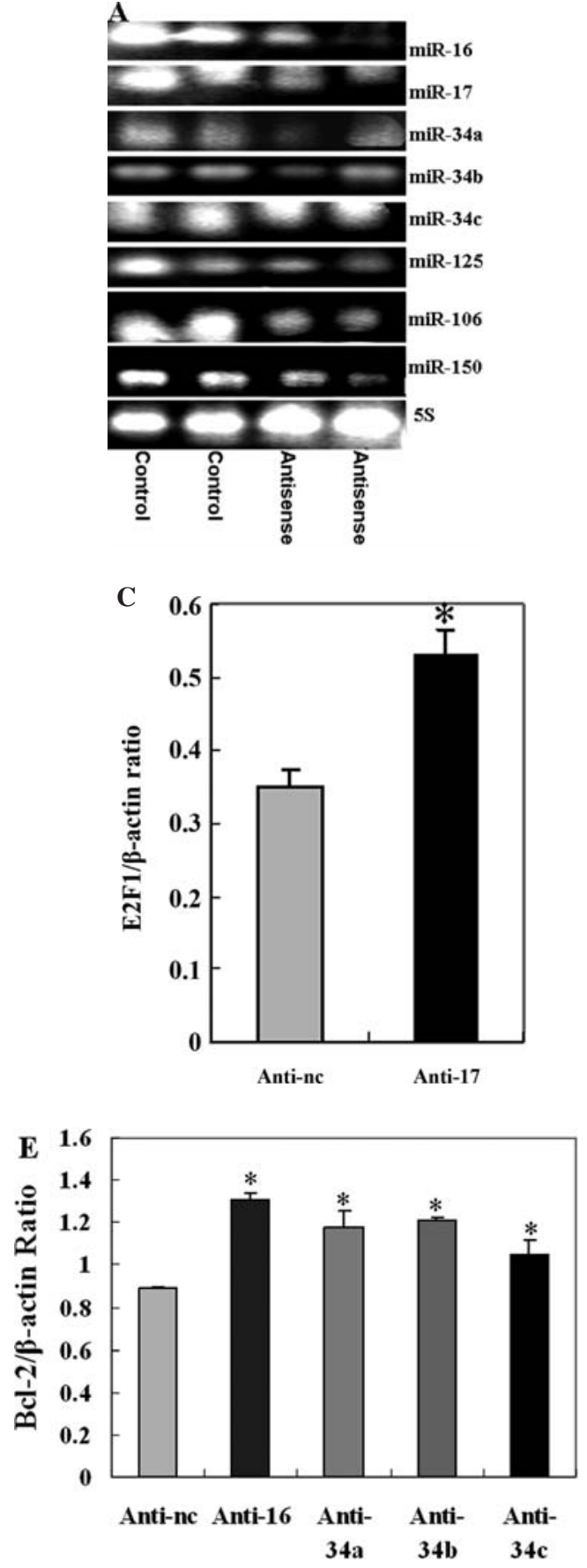

Figure 4. Correlative expression of miRNAs and oncogenes using antisense oligos (ASO). (A) RT-PCR, (B) real-time PCR. Correlative expression of (C) E2F1 and its targeted miR-17-5p, (D) E2F3 and its targeted miRNAs and (E) Bcl-2 and its targeted miRNAs (miR-16, 34a-c) using ELISA is shown. *Significant difference $(\mathrm{p}<0.05)$.

Our results further showed that RB1 expression was down-regulated after cells were treated with miR-106a RNA, but RB1 was up-expressed when miR-106 was inhibited by anti-106, indicating that it plays an important role in the induction of apoptosis by cisplatin in K562 cells (Figs. 5D and 6A). P53 gene expression was found to be regulated by miR-150 and up-expressed when miR-150 was inhibited by anti-150 (Figs. 5E and 6B), which indicated that miR-150 was an upstream regulator of P53 and down-regulated P53 expression. This suggests that miR-16, miR-34a-c, miR-17-5p,
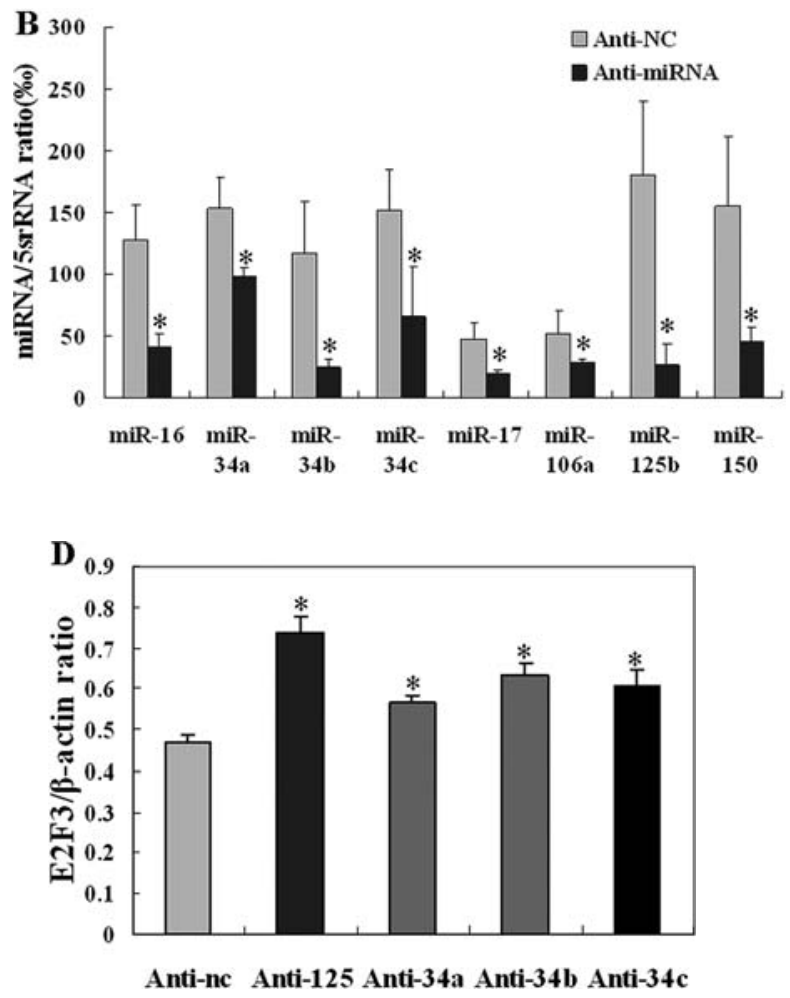

miR-106 and miR-150 may be upstream regulators for their target genes.

Oncogenes and tumor suppressor genes relevant to miR-106 and miR-150. As tumor suppressor genes, RB1 and P53 can inhibit expression of the oncogenes BCL2, E2F1 and E2F3 through different manners $(14,15)$. we investigated whether these oncogenes were regulated by RB1 and P53 through their targeted miRNAs miR-106 and miR-150. Our results indicated that E2F3 was down-expressed when RB1 expression increased, while a change in BCL2 and E2F1 expression was not noted after anti-106 treatment (Fig. 6A). We further proposed that miR-34a-c was a downstream factor of RB1 which down-expresses E2F3 expression. miR34a-c expression was detected after anti-106 treatment. Real-time PCR showed that miR-34a-c expression was higher upon upexpression of RB1 after treatment with anti-106 (Fig. 7A), which indicates that RB1 may down-regulate E2F3 expression through miR-34a-c.

After the up-regulation of P53 expression after anti-150 treatment, BCL2 and E2F3 were found to be down-expressed significantly at different levels (Fig. 6B). Real-time PCR further indicated that miR-34a-c/miR-16 expression was upregulated after treatment with anti-150 (Fig. 7B), suggesting that P53 may down-regulate BCL2 or E2F1 expression through the miR-34a-c/miR-16 pathway.

\section{Discussion}

The aim of this study was to investigate the potential mechanism of cisplatin induction of apoptosis in leukemia cells through miRNAs. Therefore, the expression of miRNAs and their targeting oncogenes or tumor suppressor genes was studied in K562 cells after cisplatin treatment. We first 

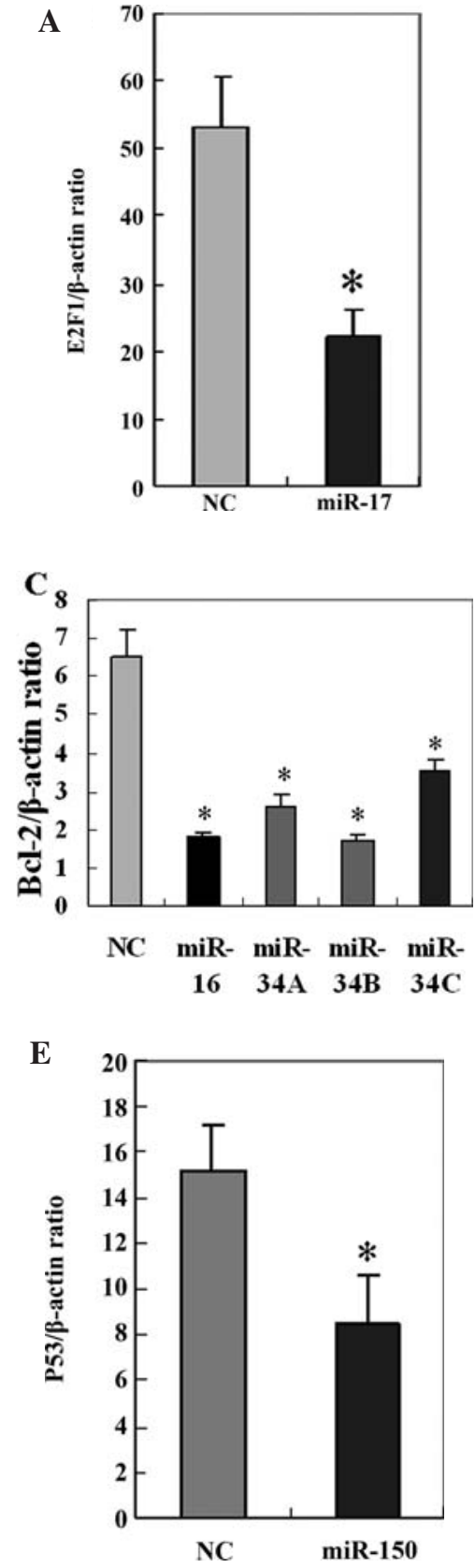

Figure 5. Expression of E2F1, E2F3, BCL2, RB1 and P53 genes regulated by miRNAs. Detection of the expression of (A) E2F1, (B) E2F3, (C) BCL2, (D) RB1 and (E) P53. "Significant difference $(\mathrm{p}<0.05)$.

investigated whether cisplatin induces K562 cell apoptosis by inhibiting oncogene expression and enhancing tumor suppressor gene expression. BCL2, E2F1, E2F3 RB1 and P53 are common genes involved in most tumor formation. Therefore, these genes were chosen for this study in K562 cells after cisplatin treatment. To confirm the relationship between miRNAs and their targeting genes, possible miRNAs related to the above genes were predicted by microRNA TargetScan software. Our results further showed that K562 cell apoptosis was attributed to miRNAs (miR-16, miR-34a-c, miR-17-5p and miR-125) which inhibit oncogene (BCL2, E2F1 and E2F3) expression and to the downregulation of miR-106 and miR-150 expression which induces high expression of tumor suppressor genes (RB1 and P53).
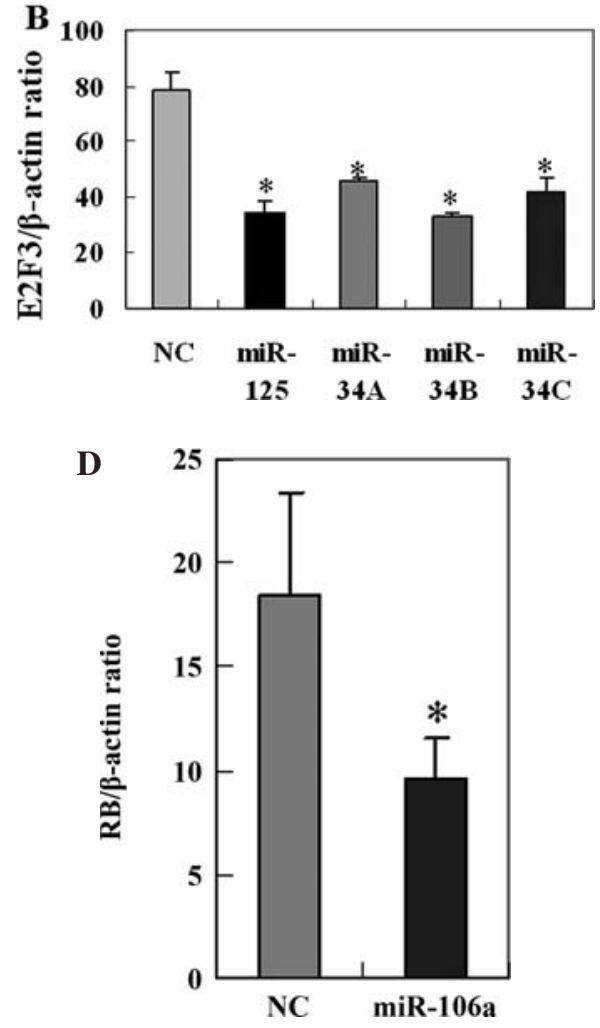

We also investigated whether expression of BCL2, E2F1, E2F3, RB1 and P53 genes was regulated by their targeted miRNAs as predicted by microRNA TargetScan software. After cisplatin treatment, miRNAs and their relevant genes were individually studied. We found that BCL2 was downregulated by miR-16 after cisplatin treatment, which indicates that miR-16 and BCL2 are involved in the mechanism of cisplatin-induced K562 cell apoptosis. This finding was further confirmed using ASO to inhibit miR-16 expression. A previous study also showed that $m i R-15$ and $m i R-16$ were natural antisense Bcl-2 interactors which could be used for therapy in tumors overexpressing Bcl-2 (16). In MEG-01 cells transfected with pSR-miR-15/16-WT, a reduction in $\mathrm{Bcl}-2$ protein levels by miRNAs was sufficient to initiate the apoptotic process. These results support the therapeutic potential of antisense Bcl-2 as a chemosensitizer for cancer therapy. Moreover, our identification of miR-16 as a tumor suppressor gene was also supported by Calin et al, who reported that miR-15 and miR-16 lie within a small region of chromosome $13 \mathrm{q} 14$ which was found to be deleted in more than $65 \%$ of chronic lymphocytic leukemia (CLL) samples (17). The allelic loss in this region correlates with downregulation of both miR-15 and miR-16 expression suggesting that these genes represent targets of inactivation by allelic loss in CLL. Our study also demonstrated that miR-34a/34b inhibits BCL2 expression after the addition of cisplatin, similar to the down-regulation of the anti-apoptotic protein BCL2 by miR-34 in other cells (18).

In this study, miR-17-5p was found to be an upstream factor which regulates E2F1 expression and is involved in the mechanism of cisplatin-induced K562 cell apoptosis. miR-17-5p was found to directly regulate expression of the pro-proliferative transcription factor E2F1 (19). The altered level of miR-17-5p modified E2F1 activity, leading to the 

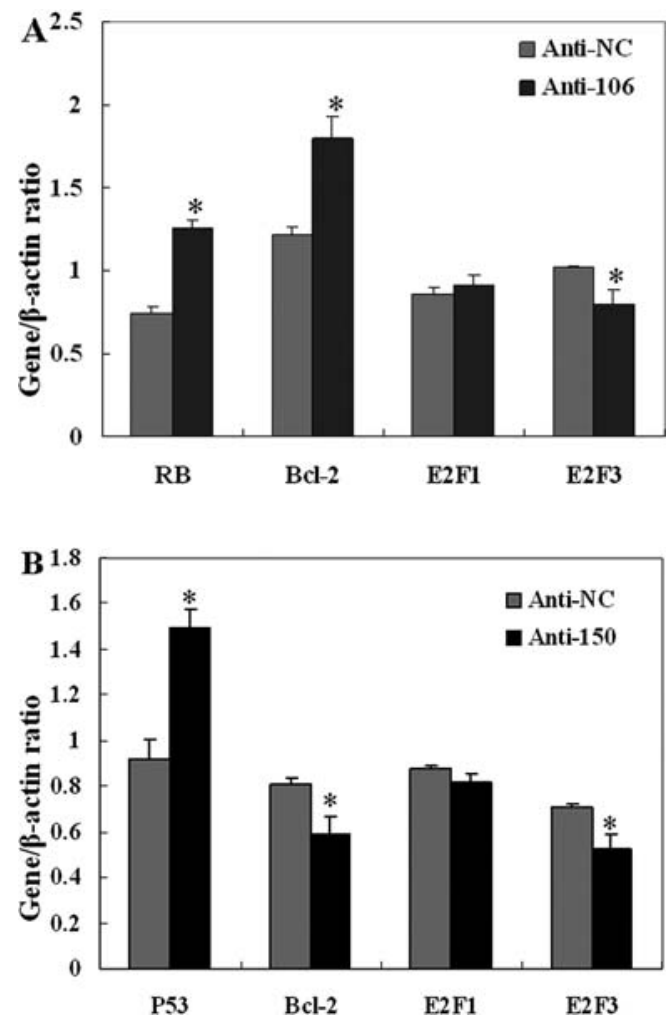

Figure 6. Correlative expression of miRNA and tumor suppressor genes with ASO. Correlative expression of (A) RB1 and miR-106 and (B) P53 and miR-150 and their downstream factors after ASO treatment. *Significant difference $(\mathrm{p}<0.05)$.

promotion of cell proliferation and decreased cell death. Another E2F family member, E2F3, plays an important role in several apoptosis pathways, which have been experimentally validated as miR-34 targets by Western blotting (20). Apart from miR34a-c, our results also confirmed that miR-125 is an upstream miRNA which regulates gene E2F3 expression and is involved in the mechanism of cisplatin-induced K562 cell apoptosis.

The retinoblastoma (RB) family of tumor suppressors and the E2F family of transcription factors are involved in the maintenance of many cellular processes including regulation of the cell cycle, DNA replication, DNA repair and apoptosis (21). Inactivation of RB1 and E2F proteins has been linked to tumorigenesis. Considering the role of RB1, we studied the association between miR-106a/miR-20 and RB1 expression using TargetScan analysis. Our results further confirmed that RB1 plays an important role in cisplatin-induced K562 cell apoptosis, which is regulated by miR-106a. Similarly, Pogribny et al reported that the increased expression of miR-106a and the associated decreased level of RB1 protein results in a more 'relaxed' heterochromatin organization, which markedly decreases genome stability (22). Our results also indicate that miR-106a is an upstream factor of RB1, which regulates RB1 and inhibits E2F3 gene expression to participate in cisplatin-induced K562 cell apoptosis.

Although numerous protein factors that control P53 have been identified, the role of miRNAs in regulating P53 remains unexplored. In our study, we demonstrated that miR-150 is an upstream factor of P53 and down-regulates P53 expression.
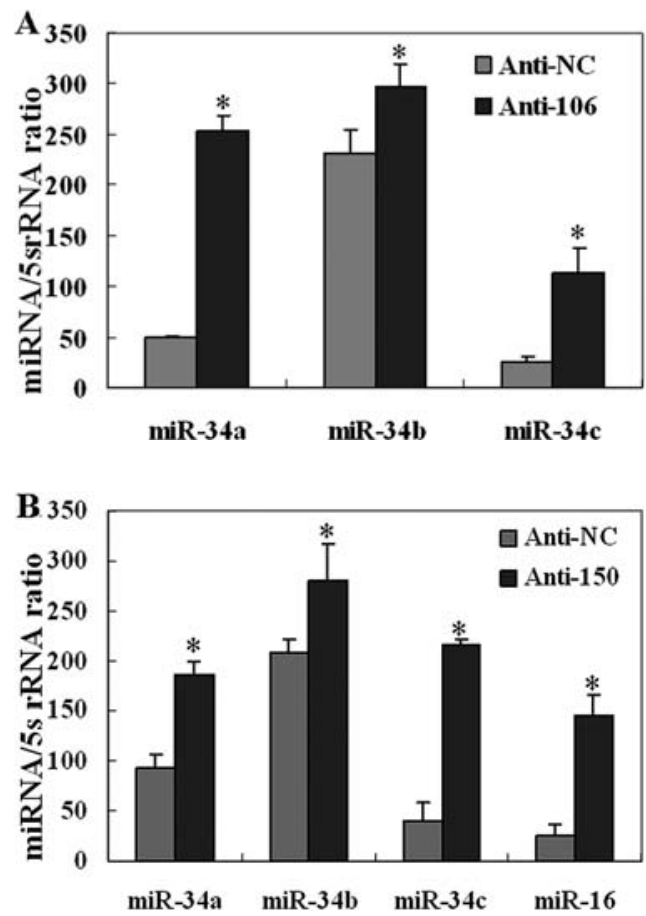

Figure 7. miRNA expression downstream of RB1 and P53 was detected by real-time PCR. (A) Expression of miR-34a-c after treatment with anti-106. (B) Expression of miR-34a-c and miR-16 after treatment with anti-150. *Significant difference $(\mathrm{p}<0.05)$.

Conversely, miR-29 family members (miR-29a-c) were found to up-regulate P53 levels and induce apoptosis in a P53-dependent manner (23). We also found that cisplatin induced miR-150 down-expression, which up-regulated P53 and inhibited E2F3 gene or BCL2 expression leading to K562 cell apoptosis. Real-time PCR further indicated that P53 down-regulated BCL2 or E2F1 expression through the miR-34a-c/miR-16 pathway. Moreover, it has been reported that members of the miR-34 family are direct p53 targets, which induce apoptosis, cell cycle arrest and senescence (24). Both bioinformatic and experimental approaches have been used to address this issue and are consistent with the predicted p53-miR-34 circuit, where several miR-34regulated genes are repressed after p53 activation (25). Microarray analysis showed that the induction of miR-34s led to the down-regulation of hundreds of mRNAs, including CDK4, CDK6, Bcl-2, cyclin E2 and E2F3 and have been experimentally validated as miR-34 targets by Western blotting.

In conclusion, this study demonstrated that cisplatin induces apoptosis in K562 cells by down-regulating the oncogenes BCL2, E2F1 and E2F3 through miRNAs, or by reducing miR-106 to up-regulate $\mathrm{RB} 1$, or by inhibiting miR-150 to increase P53 expression.

\section{Acknowledgements}

This study was supported by the National Natural Science Foundation (no. 30801324), the Shandong Science and Technology Committee (no. 2007BS03048, ZR2009CQ033) and the Yantai Science and Technology Committee (no. 2007153) of China. 


\section{References}

1. Dedoussis GV, Mouzaki A, Theodoropoulou M, Menounos P, Kyrtsonis MC, Karameris A and Maniatis A: Endogenous interleukin 6 conveys resistance to cis-diamminedichloroplatinum-mediated apoptosis of the K562 human leukemic cell line. Exp Cell Res 249: 269-278, 1999.

2. Hasinoff BB, Wu X and Yang Y: Synthesis and characterization of the biological activity of the cisplatin analogs, cis-PtCl2 (dexrazoxane) and cis-PtCl2 (levrazoxane), of the topoisomerase II inhibitors dexrazoxane (ICRF-187) and levrazoxane (ICRF-186). J Inorg Biochem 98: 616-624, 2004.

3. Shulga N, Wilson-Smith R and Pastorino JG: Hexokinase II detachment from the mitochondria potentiates cisplatin-induced cytotoxicity through a caspase-2-dependent mechanism. Cell Cycle 8: 3355-3364, 2009.

4. Farnebo L, Jedlinski A, Ansell A, Vainikka L, Thunell LK, Grénman R, Johansson AC and Roberg K: Proteins and single nucleotide polymorphisms involved in apoptosis, growth control, and DNA repair predict cisplatin sensitivity in head and neck cancer cell lines. Int J Mol Med 24: 549-556, 2009.

5. Lau NC, Lim LP, Weinstein EG and Bartel DP: An abundant class of tiny RNAs with probable regulatory roles in Caenorhabditis elegans. Science 294: 858-862, 2001.

6. Ghosh Z, Chakrabarti J and Mallick B: miRNomics - the bioinformatics of microRNA genes. Biochem Biophys Res Commun 363: 6-11, 2007

7. Katada T, Ishiguro H, Kuwabara Y, Kimura M, Mitui A, Mori Y, Ogawa R, Harata K and Fujii Y: microRNA expression profile in undifferentiated gastric cancer. Int J Oncol 34: 537-542, 2009.

8. Bartel DP: MicroRNAs: genomics, biogenesis, mechanism, and function. Cell 116: 281-297, 2004.

9. He L, Thomson JM, Hemann MT, Hernando-Monge E, Mu D, Goodson S, Powers S, Cordon-Cardo C, Lowe SW, Hannon GJ and Hammond SM: A microRNA polycistron as a potential human oncogene. Nature 435: 828-833, 2005.

10. Voorhoeve PM, le Sage C, Schrier M, Gillis AJ, Stoop H, Nagel R, Liu YP, van Duijse J, Drost J, Griekspoor A, Zlotorynski E, Yabuta N, De Vita G, Nojima H, Looijenga LH and Agami R: A genetic screen implicates miRNA-372 and miRNA-373 as oncogenes in testicular germ cell tumors. Cell 124: 1169-1181, 2006.

11. Møller MB, Kania PW, Ino Y, Gerdes AM, Nielsen O, Louis DN, Skjødt K and Pedersen NT: Frequent disruption of the RB1 pathway in diffuse large B cell lymphoma: prognostic significance of E2F-1 and p16INK4A. Leukemia 14: 898-904, 2000.

12. Wang L, Pal S and Sif S: Protein arginine methyltransferase 5 suppresses the transcription of the RB family of tumor suppressors in leukemia and lymphoma cells. Mol Cell Biol 28: 6262-6277, 2008.
13. Horwich MD and Zamore PD: Design and delivery of antisense oligonucleotides to block microRNA function in cultured Drosophila and human cells. Nat Protoc 3: 1537-1549, 2008.

14. Angus SP, Mayhew CN, Solomon DA, Braden WA, Markey MP, Okuno Y, Cardoso MC, Gilbert DM and Knudsen ES: RB reversibly inhibits DNA replication via two temporally distinct mechanisms. Mol Cell Biol 24: 5404-5420, 2004.

15. He L, He X, Lowe SW and Hannon GJ: microRNAs join the p53 network - another piece in the tumour-suppression puzzle. Nat Rev Cancer 7: 819-822, 2007.

16. Cimmino A, Calin GA, Fabbri M, Iorio MV, Ferracin M, Shimizu M, Wojcik SE, Aqeilan RI, Zupo S, Dono M, Rassenti L, Alder H, Volinia S, Liu CG, Kipps TJ, Negrini M and Croce CM: miR-15 and miR-16 induce apoptosis by targeting BCL2. Proc Natl Acad Sci USA 102: 13944-13949, 2005.

17. Calin GA, Dumitru CD, Shimizu M, Bichi R, Zupo S, Noch E, Aldler H, Rattan S, Keating M, Rai K, Rassenti L, Kipps T, Negrini M, Bullrich F and Croce CM: Frequent deletions and down-regulation of micro-RNA genes miR 15 and miR16 at $13 q 14$ in chronic lymphocytic leukemia. Proc Natl Acad Sci USA 99: 15524-15529, 2002.

18. Bommer GT, Gerin I, Feng Y, Kaczorowski AJ, Kuick R, Love RE, Zhai Y, Giordano TJ, Qin ZS, Moore BB, MacDougald OA, Cho KR and Fearon ER: p53-mediated activation of miRNA34 candidate tumor-suppressor genes. Curr Biol 17: 1298-1307, 2007.

19. O'Donnell KA, Wentzel EA, Zeller KI, Dang CV and Mendell JT: c-Myc-regulated microRNAs modulate E2F1 expression. Nature 435: 839-843, 2005.

20. Welch C, Chen Y and Stallings RL: MicroRNA-34a functions as a potential tumor suppressor by inducing apoptosis in neuroblastoma cells. Oncogene 26: 5017-5022, 2007.

21. Classon M and Harlow E: The retinoblastoma tumour suppressor in development and cancer. Nat Rev Cancer 2: 910-917. 2002.

22. Pogribny IP, Tryndyak VP, Boyko A, Rodriguez-Juarez R, Beland FA and Kovalchuk O: Induction of microRNAome deregulation in rat liver by long-term tamoxifen exposure. Mutat Res 619: 30-37, 2007.

23. Park SY, Lee JH, Ha M, Nam JW and Kim VN: miR-29 miRNAs activate p53 by targeting p85 alpha and CDC42. Nat Struct Mol Biol 16: 23-29, 2009.

24. Chang TC, Wentzel EA, Kent OA, Ramachandran K, Mullendore M, Lee KH, Feldmann G, Yamakuchi M, Ferlito M, Lowenstein CJ, Arking DE, Beer MA, Maitra A and Mendell JT: Transactivation of miR-34a by p53 broadly influences gene expression and promotes apoptosis. Mol Cell 26: 745-752, 2007.

25. Spurgers KB, Gold DL, Coombes KR, Bohnenstiehl NL, Mullins B, Meyn RE, Logothetis CJ and McDonnell TJ: Identification of cell cycle regulatory genes as principal targets of p53-mediated transcriptional repression. J Biol Chem 281: 25134-25142, 2006. 